\title{
Role of Glutamine in Protection of Intestinal Epithelial Tight Junctions
}

\author{
Radha Krishna Rao* and Geetha Samak
}

Department of Physiology, University of Tennessee Health Science Center, Memphis, TN, USA

\begin{abstract}
Glutamine, a conditionally essential amino acid, is consumed predominantly in the gastrointestinal tract as a source of energy, particularly under the conditions of trauma, sepsis and surgery. In this article, we discuss the unique role of glutamine in the preservation of epithelial barrier function in the gastrointestinal tract. Glutamine supplementation protects the gastrointestinal mucosal homeostasis during total parenteral nutrition, diarrhea, radiation injury, starvation, sepsis and trauma. A significant body of evidence indicates that glutamine preserves the gut barrier function and prevents permeability to toxins and pathogens from the gut lumen into mucosal tissue and circulation. Recent studies demonstrated that the mucosal barrier protective effect of glutamine relates to its effect on preservation of epithelial tight junction integrity. The current understanding of glutamine-mediated protection of intestinal epithelial tight junction integrity and the potential mechanisms involved in this protective effect of glutamine are discussed.
\end{abstract}

Keywords: Glutamine, epithelium, barrier function, tight junction, EGF receptor, acetaldehyde.

\section{INTRODUCTION}

In addition to its important role in digestion, absorption and secretion, the gastrointestinal epithelium serves as a barrier to the diffusion of toxins, allergens and pathogens from the luminal contents into the interstitial tissue. Barrier disruption and diffusion of noxious substances are known to induce mucosal inflammation and tissue injury. In fact, the disruption of gut barrier function plays a crucial role in the pathogenesis of numerous gastrointestinal diseases such as inflammatory bowel disease (IBD), irritable bowel syndrome (IBS), celiac disease and infectious enterocolitis. The specialized junctional complexes called tight junctions provide the intestinal epithelial barrier function. Loss of tight junction integrity and increased intestinal permeability to macromolecules are associated with the pathogenesis of IBD, IBS and celiac disease. Mucosal protective factors such as growth factors and nutrients preserve the gut barrier integrity and are beneficial in the treatment of various gastrointestinal diseases. L-Glutamine the most abundant amino acid in blood plays a vital role in the maintenance of mucosal integrity. Glutamine is traditionally termed as a nonessential amino acid, is now considered a "conditionally essential" amino acid. Its consumption in small bowel mucosa exceeds the rate of production during catabolic stress such as trauma, sepsis and post surgery $[1,2]$. In the small bowel mucosa, glutamine is an unique nutrient providing fuel for metabolism, regulating cell proliferation, repair and maintaining the gut barrier functions [3]. The focus of this article is on the role of L-glutamine in the preservation of gut barrier function and the epithelial tight junction integrity and gut barrier function.

*Address correspondence to this author at the Department of Physiology University of Tennessee, 894 Union Avenue Memphis, TN 38163, USA;

Tel: (901) 448-3235; Fax: (901) 448-7126; E-mail: rrao2@uthsc.edu

\section{L-GLUTAMINE, THE MOST ABUNDANT AMINO ACID IN THE BIOLOGICAL FLUIDS}

L-Glutamine is an amide of glutamic acid with amine as the functional group. It is the most abundant amino acid in both intracellular and extracellular compartments produced by the action of glutamine synthase as it is required for number of cellular functions. The intracellular concentration of L-glutamine range from $2 \mathrm{mM}$ to $20 \mathrm{mM}$ [2], where as its concentration in extracellular fluid and plasma is about 0.7 $\mathrm{mM}[4,5]$. The plasma concentration of L-glutamine is significantly reduced under the conditions of extraneous exercise $[2,6,7]$ and under severe shock and trauma $[8,9]$. Although adequate glutamine is produced in the body to maintain the normal physiological functions in the cell, the depletion of glutamine under conditions of exercise and stress makes the body depend on exogenous glutamine to supplement the body glutamine pool to meet the requirement. Therefore, L-glutamine is a conditionally essential amino acid [1].

\section{L-GLUTAMINE HAS MULTIPLE PHYSIOLOGICAL FUNCTIONS}

Glutamine plays multiple roles in the maintenance of physiological homeostasis of diverse organs and cell types. It is best known for its ability to serve as a source of fuel for the cells such as enterocytes, renal epithelial cells, hepatocytes, neurons, immune cells, $\beta$-cells of pancreas [3]. Glutamine metabolism plays multiple roles in nitrogen balance, regulation of glucose metabolism and acid base homeostasis. It is quantitatively the most important donor of ammonia in kidney and liver, and plays a role in maintaining the acidbase balance of body fluids. Alkalosis with elevated ammonia level is associated with increased production of glutamine, while during acidosis glutamine is broken down to glutamate and ammonia serving to elevate plasma $\mathrm{pH}$ 
[10-12]. It is a major transporter of nitrogen from the sites of synthesis (skeletal muscle, liver and lung) to the sites of utilization (kidney, intestine, neuron and immune cells) and serves as a nontoxic ammonia shuttle in the body [13, 14].

Glutamine is utilized at a high rate in rapidly dividing immune cells and promotes many functional activities of immune cells such as T-cell proliferation, B-cell differentiation, phagocytosis, antigen presentation, cytokine production and neutrophil superoxide production $[15,16]$. Muscle tissue is a major site of glutamine synthesis where it forms the anabolic precursor for muscle growth. Glutamine is essential for the growth, survival and physiological health of actively dividing cells such as enterocytes, fibroblasts and lymphocytes [17]. It is also an important osmolyte for cell volume control and shown to increase hepatocyte cell volume by eliciting anabolic process [6, 18, 19].

L-Glutamine is the precursor for synthesis of few peptides, amino sugars, purines, pyrimidines, nucleic acids and other nitrogenous compounds in the cells. The synthesis of glutathione, a major endogenous antioxidant in mammalian cells, requires glutamine as a precursor. Glutathione protects most cells from oxidative injury. Several metabolic products derived from glutamine also include neurotransmitter, proline and hexosamines [20] Glutamine/glutamate is a substrate involved in the ureagenesis in liver and gluconeogenesis in liver and kidney.

\section{PATHOPHYSIOLOGY OF GLUTAMINE DEFICIENCY}

Glutamine is a non-essential amino acid under normal physiological conditions, as it is produced in the body in adequate amounts. However, under conditions of severe infections, physical trauma, radiation-induced damage and major bums the physiological level of glutamine is inadequate and therefore required to be supplemented with dietary glutamine. Normal range of plasma glutamine level is 500$750 \mu \mathrm{mol} / \mathrm{L}$. Prolonged exhaustive exercise leads to nearly $25 \%$ drop in plasma glutamine level. Plasma glutamine level falls also during fasting and in patients with untreated diabetes mellitus. In all these cases catabolic stress occurs by rise in plasma cortisol and glucagon by enhancing the physiological demand for glutamine for gluconeogenesis. Heavy physical training leads to reduction in plasma glutamine level below $500 \mu \mathrm{mol} / \mathrm{L}$. The recovery of such deficit requires a long period, which is the causing factor in the development of overtraining syndrome among athletes [2, 7]. Certain pathological conditions leading to catabolic stress where intracellular glutamine levels may drop below $50 \%$ and plasma concentration below $30 \%$, body requirement for glutamine overwhelms the capacity of body for de novo synthesis of glutamine [21], and therefore depends on dietary glutamine supplementation. Sepsis and other severe illnesses leading to multiple organ dysfunction results from nitric oxide and peroxynitrite generation leading to oxidant injury in a glutamine-deficient environment. Similar type of local tissue injury is seen in ischemia and reperfusion [22, 23]. Therefore, depletion of tissue glutamine can be viewed as a compromised body defense system, which is a likely mechanism in the pathogenesis of various clinical conditions.

Glutamine is essential also for the growth and viability of cell lines in culture, and requires that it is present in the me- dium 10-100 fold in excess of other amino acids. Presence of glutamine in the medium cannot be substituted with glutamic acid or glucose $[2,24]$. Glutamine deficiency leads to cell death in many human cell lines. Enteral administration of glutamine stimulates intestinal mucosal protein synthesis and protects enterocytes from apoptosis. Animal and clinical studies have shown that glutamine deprivation leads to villous atrophy, mucosal ulcerations and cell necrosis in the small intestine [25]. There is an increased susceptibility to infections due to decrease in plasma glutamine concentration which impairs the functioning of immune cells [26].

\section{GASTROINTESTINAL MUCOSAL PROTECTION BY GLUTAMINE}

Gastrointestinal mucosa is lined with multifunctional, rapidly proliferating epithelial cells. They form a primary interface between luminal contents and the interstitial tissue. These cells are dependent on both luminal and systemic sources for their nutrition and are affected by intra and extraluminal nutrient intake. During the normal life time 60 tons of food pass through gastrointestinal tract posing continuous threat to the integrity of gastrointestinal tract and whole body. Hence this organ is often under the challenge of inflammatory diseases and cancer [27]. Under normal physiological conditions, proteases, dietary components, drugs, microbes and other factors usually cause minor damage to mucosa. Gastrointestinal mucosal integrity is quickly restored and maintained by cell proliferation, migration, restitution and differentiation. A host of growth factors and regulatory peptides play protective and healing roles to meet this challenge. Furthermore, the salivary secretions, gastrointestinal mucosal secretions and factors of intra-luminal microflora jointly preserve the normal homeostasis [28, 29]. The enteral feeding appears to be the primary stimulus for the regulation of proliferative response in the intestinal tract, which is accomplished mainly by the L-glutamine. Gut mucosa is the major site of Glutamine metabolism. It is an important anoplerotic substrate in the mucosal cells and forms important source of energy accounting to about $35 \%$ of the total carbon dioxide produced from various substrates in the intestinal mucosa. Glutamine also mediates several other protective influences on the gastrointestinal tract and forms an important dietary component to maintain gut mucosal integrity [30-32].

Gastrointestinal tract plays a central role in catabolic response after injury and infection. Prolonged stress and trauma leads to a drop in body glutamine pool causing mucosal atrophy. Oral Glutamine supplementation supports gastrointestinal mucosal growth and prevents the mucosal and villous atrophy in patients receiving total parenteral nutrition (TPN) [33, 34]. Animals when supplemented with glutamine during TPN also showed a dose-dependent increase in mucosal weight. Glutamine facilitates enteral absorption of nutrients and electrolytes in animals with experimental diarrhea [35]. It also lessens the severity of diarrhea by enhancing water and salt intake. It protects the gut epithelium from ammonia-induced cell death [36-39].

Glutamine prevents the gastrointestinal injury induced by radiation, which is of importance under the conditions of radiation therapy in cancer patients. Radiation and chemo- 
therapy causes bowel injury and reduced mucosal lymphocyte count $[40,41]$. Administration glutamine-rich diet protects the gut mucosa from injury and ulceration caused by radiation. L-glutamine supplementation raises the level of mucosal and plasma glutathione (GSH). Enteral glutamine also stimulates mucosal protein synthesis during sepsis and attenuates ubiquitin-dependent proteolysis and improves the protein balance of gut. Mechanism of oral glutamine supplementation-induced gut mucosal protection against starvation, stress, trauma, radiation and other pathological conditions involves increase in the rate of protein synthesis and decrease in proteolysis [42, 43].

Glutamine is a major source of energy for proliferation and differentiation of intestinal epithelial cells [44]. Dietary supplementation of glutamine found to be beneficial in maintenance of normal intestinal villous morphology and average daily body weight gain in weaned piglets [45]. Lack of glutamine attenuated the growth of two types of intestinal epithelial cells, IEC-6 and Caco-2 in culture in vitro, which was reversed by the addition of nucleosides suggesting the role of glutamine amide nitrogen pool for the synthesis of nucleotide and glucosamine in the intestinal mucosa [46]. Glutamine is necessary for enterocyte proliferation, fluid and electrolyte absorption and mitogenic response to growth factors. It is required for maximal stimulation of intestinal epithelial cell proliferation by EGF [47, 48]. EGF activates Glutamine transport activity across the intestinal epithelial membrane through protein kinase $\mathrm{C}$ (PKC) and MAP kinase (MAPK)-mediated cell signaling [49]. Due to its multiple roles in the gastrointestinal tract glutamine demand in the gastrointestinal mucosa is more than $15 \mathrm{~g} /$ day, which is obtained mainly from systemic circulation as there is very little glutamine synthase activity in the gastrointestinal mucosa. Hence gastrointestinal mucosa derives glutamine formed in other tissue and also from diet for its metabolism [50]. The evidence available to support the beneficial effect in maintenance of gastrointestinal mucosal homeostasis is summarized in Table $\mathbf{1}$.

\section{GUT PERMEABILITY AND GLUTAMINE}

Gastrointestinal mucosal epithelium provides a structural and immunological barrier against the broad spectrum of noxious and immunogenic substances present the lumen of the gut. Compromised intestinal mucosal integrity and breakdown of gastrointestinal mucosal barrier function, a condition generally referred to as "Leaky Gut Syndrome", are associated with starvation, injury, infection, immunosuppression, chemotherapy, and lack of enteral feedings, radiation and other types of stress. Disruption of gut mucosal integrity and barrier dysfunction results in increased permeability to allergens, toxins and pathogens, leading to immunological stress response and inflammation [28, 34]. Severe trauma and bum increases intestinal permeability to bacteria and endotoxins leading to sepsis and multiple organ failure [51]. A rapid resealing of gut epithelial barrier function following injury under physiological conditions is essential as infection is a major cause of morbidity.

A significant body of evidence indicates that glutamine preserves the gut barrier function and prevents permeability to toxins and pathogens under various conditions of gastrointestinal mucosal injury. Glutamine is considered the most important nutrient for healing of 'leaky gut syndrome' because it is the preferred fuel for enterocytes and colonocytes [52]. Low level of serum Glutamine concentration correlated with intestinal barrier disruption, inflammation and diarrheal diseases among children [53, 54]. Glutamine supplementation causes a profound improvement in intestinal barrier function in highly stressed patients and patients in TPN. Glutamine-fortified parenteral and enteral diets significantly improve the intestinal morphology and function $[32,55,56]$. Factors triggering the increase in intestinal mucosal permeability during trauma and illness include oxidative stress, pro inflammatory cytokines, hypoxia and reduction in intramucosal $\mathrm{pH}$. Clinical and animal studies have demonstrated that the administration of glutamine before or immediately after surgery reduced the intensity of increase in intestinal permeability and systemic inflammatory response [57]. Glutamineinduced recovery in intestinal barrier function by reducing bacterial translocation was demonstrated in laboratory animals [58]. It stabilizes intestinal permeability and reduces pancreatic infection in acute experimental pancreatitis [59].

Several animal studies demonstrated that experimentallyinduced hyper permeability can be alleviated by the addition of glutamine or glutamine peptide leading to improved gut barrier function as well as immune function in the gut [56]. Gut barrier dysfunction and endotoxemia are associated with the pathogenesis of inflammatory bowel diseases, such as ulcerative colitis and Crohn's disease. Glutamine supplementation significantly reduced clinical and endoscopic scores in patients with ulcerative colitis [60]. Therefore, both experimental studies and clinical observations indicate that glutamine plays a crucial role in maintenance and restoration of gut barrier function.

\section{REGULATION OF EPITHELIAL TIGHT JUNCTIONS BY GLUTAMINE}

The epithelial tight junctions constitute the major component of gut barrier function, which acts as physical and functional barrier against the paracellular penetration of macromolecules from the lumen [61]. Therefore, disruption of tight junctions is an initial event associated with the pathogenesis of many gastrointestinal diseases. The tight junction is organized by four types of transmembrane proteins, occludin, claudins, tricellulin and junctional adhesion molecules, which interact with the scaffold proteins such as ZO-1, ZO-2 and ZO-3 [62, 63]. ZO-1 anchors the transmembrane proteins of tight junctions to the actin cytoskeleton and interacts with other tight junction proteins. Tight junction proteins interact with numerous signaling proteins that regulate tight junction assembly and maintenance, indicating the potential role of intracellular signaling pathways in the regulation of epithelial tight junctions and barrier function [64].

Stress, food allergies, alcohol, antibiotics, malnutrition are some of the factors that lead to leaky gut syndrome. Leaky gut or increased intestinal epithelial permeability has been implicated in the pathogenesis of several gastrointestinal diseases such as food allergies, IBD and IBS [65, 66]. Glutamine is likely a potential intervention strategy for these diseases, as it reduces intestinal permeability from various stressors and helps maintain the normal intestinal barrier function [41, 59, 67]. Deprivation of dietary glutamine in infant rats by inhibiting glutamine synthase resulted in in- 
Table l. Beneficial Effects of L-Glutamine

\begin{tabular}{|c|c|c|c|}
\hline Pathophysiological and Experimental Conditions & Study Model & Protective Role of L-Glutamine Supplementation & Reference \\
\hline Total parenteral nutrition & Rodent (rat) & $\begin{array}{l}\text { Prevents villous atrophy and promotes gastrointestinal mucosal } \\
\text { growth. }\end{array}$ & $\begin{array}{l}\text { Platell et al. } \\
\text { [33] }\end{array}$ \\
\hline Total parenteral nutrition & Rodent (rat) & Improves intestinal barrier function and morphology. & Li et al. [56] \\
\hline Surgical stress & Human & Decreases mucosal atrophy and improves gut barrier function. & $\begin{array}{l}\text { Wilmore et al. } \\
\text { [34] }\end{array}$ \\
\hline $\begin{array}{l}\text { Chemotherapy induced gut mucosal ulceration } \\
\text { in cancer patients. }\end{array}$ & $\begin{array}{l}\text { Database of human and } \\
\text { animal studies }\end{array}$ & Reduces mucositis and prevents chemotherapy-induced diarrhea. & $\begin{array}{l}\text { Savarese et al. } \\
{[40]}\end{array}$ \\
\hline Abdominal radiation-induced toxicity & Human & $\begin{array}{l}\text { Decreases oxidative stress and enhances mucosal lymphocyte } \\
\text { count. }\end{array}$ & $\begin{array}{l}\text { Yoshida et al. } \\
\text { [41] }\end{array}$ \\
\hline $\begin{array}{l}\text { Critically ill patients and Multiple organ } \\
\text { failure syndrome }\end{array}$ & $\begin{array}{l}\text { Database of human } \\
\text { studies }\end{array}$ & $\begin{array}{l}\text { Maintains physiology of intestinal barrier and reduces frequency } \\
\text { of infections. }\end{array}$ & $\begin{array}{l}\text { De-Souza et } \\
\text { al. [57] }\end{array}$ \\
\hline $\begin{array}{l}\text { Severe trauma and bum-induced sepsis, and } \\
\text { leaky gut syndrome }\end{array}$ & Human & Improvement of gut mucosal barrier function. & $\begin{array}{l}\text { Peng et al. } \\
{[51]}\end{array}$ \\
\hline Diarrheal diseases in children. & Human & $\begin{array}{l}\text { Decreases intestinal permeability, endotoxemia and inflammatory } \\
\text { responses. }\end{array}$ & Lima et al. \\
\hline Post operative systemic inflammatory responses & Human & Improves gut barrier function and reduces inflammatory responses. & $\begin{array}{l}\text { Quan et al. } \\
\text { [58] }\end{array}$ \\
\hline Ulcerative colitis & Guinea-pigs & Reduces oxidant injury. & $\begin{array}{l}\text { Fujita et al. } \\
\text { [55] }\end{array}$ \\
\hline Intestinal ischemia reperfusion induced leaky gut & Human Rodent (rat) & $\begin{array}{l}\text { Restoration of small bowel barrier function by increasing the level } \\
\text { of intestinal GSH. }\end{array}$ & $\begin{array}{l}\text { Harward et al. } \\
\text { [70] and Kozar } \\
\text { et al. }[71]\end{array}$ \\
\hline NSAID-induced side effects & Human & Decreases intestinal permeability changes. & $\begin{array}{l}\text { Hond et al. } \\
\text { [73] }\end{array}$ \\
\hline Experimental biliary obstruction & Rodent (rat) & Modulates gut permeability and reduces bacterial translocation. & $\begin{array}{l}\text { White et al. } \\
\text { [74] }\end{array}$ \\
\hline Dehydration therapy for diarrhea & $\begin{array}{l}\text { Clinical trials in human } \\
\text { patients }\end{array}$ & Decreases diarrhea by preserving intestinal barrier. & $\begin{array}{l}\text { Guerrant et al. } \\
{[53]}\end{array}$ \\
\hline Intestinal epithelial cell culture & IEC-6 and Caco- 2 cells & Enhances proliferation and Differentiation. & He et al. [46] \\
\hline $\begin{array}{l}\text { Acetaldehyde-induced disruption of tight junctions } \\
\text { and adherens junction in Caco- } 2 \text { cells. }\end{array}$ & Caco- 2 cell monolayer & $\begin{array}{l}\text { Protects cell monolayer barrier function by attenuating redistribu- } \\
\text { tion of tight junction and adherens junction proteins. }\end{array}$ & Seth et al. [77] \\
\hline $\begin{array}{l}\text { Acetaldehyde - induced disruption of Epithelial tight } \\
\text { junctions and adherens Junction in human colonic } \\
\text { mucosa }\end{array}$ & Human & $\begin{array}{l}\text { Preserved the epithelial tight junctions and adherens } \\
\text { junction integrity. }\end{array}$ & $\begin{array}{l}\text { Basuroy et al. } \\
{[78]}\end{array}$ \\
\hline
\end{tabular}

crease of bacterial translocation [68]. Inflammation during chronic fatigue syndrome is a result of increased gut permeability and bacterial translocation. Glutamine in combination with $\mathrm{N}$-acetyl cysteine and zinc partially restores the tight junction integrity and attenuated gut-derived inflammation [69]. Ischemia-reperfusion increases gut permeability by disrupting the epithelial tight junctions. Enteral glutamine restored the small bowel barrier function after ische$\mathrm{mia} /$ reperfusion injury in rats by elevating the level of intestinal GSH [70-72]. Glutamine supplementation was found to be beneficial in decreasing intestinal permeability induced by non-steroidal anti-inflammatory drug [73]. Intestinal permeability and bacterial translocation in an animal model of experimental biliary obstruction was attenuated by glutamine administration [74].

TPN is associated with increased jejunal permeability and glutamine supplementation prevented this effect and reduced the TPN-induced jejunal atrophy. Glutamine supplementation is of critical importance as it is related to energy supply to proliferating and differentiating enterocytes [75]. Administration of glutamine in bum-injury patients resulted in an increase in plasma glutamine concentration 
from $0.44 \mathrm{mM}$ to $0.61 \mathrm{mM}$, significantly reduced the intestinal permeability to lactulose/mannitol, and accelerated wound healing [51]. Glutamine administration improves the prognosis of critically ill patients by maintaining intestinal barrier and by reducing the frequency of infections [57].

The importance of glutamine in preserving the intestinal epithelial barrier function is further supported by several in vitro studies using the cell culture models of intestinal epithelium. Glutamine deprivation or inhibition of glutamine synthase in Caco- 2 cells in culture significantly decreased the transepithelial electrical resistance (TER) and increased the paracellular permeability of the cell monolayer [52] and increased bacterial translocation [66]. Glutamine deprivation reduced the expression of tight junction proteins, claudin-1 and occludin and induced redistribution of these protein from the intercellular junctions [76]. Our studies demonstrated that acetaldehyde, the carcinogenic metabolite of ethanol, disrupts the intestinal epithelial tight junctions. L-Glutamine prevents the acetaldehyde-induced increase in permeability to endotoxin by preventing the disruption of tight junction and adherence junction in Caco-2 cell monolayer [77]. The glutaminase inhibitor, 6-diazo-5-oxo-L-norleucine, failed to affect the glutamine-mediated protection of barrier function, indicating that this protective effect of glutamine did not require metabolism of glutamine, and that intact glutamine is involved in this protective function. Glutamine attenuated the acetaldehyde-induced redistribution of occludin, ZO-1, Ecadherin and $\beta$-catenin from the intercellular junctions. Similarly, pretreatment with L-glutamine significantly attenuated acetaldehyde-induced redistribution of occludin, ZO-1, Ecadherin and $\beta$-catenin from the intercellular junctions in human colonic mucosa [78].

\section{ROLE OF EGFR IN THE MECHANISM OF GLU- TAMINE-MEDIATED TIGHT JUNCTION REGULA- TION}

The molecular mechanisms regulating the effects of glutamine on intestinal barrier function is poorly understood. The lack of an effect of glutaminase inhibitor on glutaminemediated protection of barrier function indicated that the intact glutamine is responsible for the protective function. The delineation of signaling pathways involved in glutamine mediated-protection of intestinal barrier function may include many routes vowing to its multi-faceted beneficial effects. Our study on the effect of L-glutamine on acetaldehyde-induced disruption of tight junction and increase in paracellular permeability clearly demonstrated that Lglutamine prevents acetaldehyde-induced disruption of the tight junction and increase in the permeability in Caco-2 cell monolayer by an EGF receptor-dependent mechanism $[77,78]$.

EGF is a peptide growth factor of 53 amino acids. EGF is secreted in saliva and other gastrointestinal secretions at high concentrations [79]. EGF is an important gastrointestinal mucosal protective factor that protects the gastrointestinal mucosa from various insults $[79,80]$. Our studies indicated that EGF prevents acetaldehyde-induced disruption of tight junction and adherens junctions and reduce the paracellular permeability in Caco-2 cell monolayer by a phospholipase $\mathrm{C} \gamma$, protein kinase $\mathrm{C}$ (PKC) and MAP kinase (MAPK)dependent mechanisms [81-83]. The protection of tight junc- tion and adherens junctions from acetaldehyde by Lglutamine was also mediated by PKC and MAPK-dependent mechanism [77]. The protective effect of L-glutamine on acetaldehyde-induced permeability is mediated by a transactivation of EGF-receptor tyrosine kinase activity. A selective inhibitor of EGF receptor tyrosine kinase, AG 1478 significantly attenuated the glutamine-mediated prevention of acetaldehyde-induced reduction of the levels of tight junction and adherens junction proteins in detergent-insoluble fraction of Caco-2 cell monolayer and human colonic mucosa $[77,78]$. L-Glutamine induces a rapid tyrosine phosphorylation of EGF receptor [77, 78]. These studies indicated that Lglutamine protects tight junction barrier function by turning on PKC and MAPK-mediated cell signaling via transactivation of EGF receptor. The mechanism associated with EGF receptor transactivation by glutamine is unclear. However, our preliminary study (unpublished) indicates that extracellular ligand-binding domain is required for this EGF receptor transactivation. Therefore, we speculate that L-glutamine induces release of EGF receptor ligands into the extracellular medium. The signaling mechanisms associated with Lglutamine-mediated protection of intestinal epithelial tight junctions is summarized in Fig. (1).

Furthermore, a recent study demonstrated that glutamine deprivation alters intestinal tight junctions via a P13K/Aktmediated pathway in Caco-2 cells. Deprivation of Glutamine increased phospho-Akt protein, while glutamine supplementation enhanced the barrier function of Caco-2 monolayer $[84,85]$.

\section{SUMMARY AND PERSPECTIVE}

L-Glutamine is the most abundant and conditionally essential amino acid due to body's inability to synthesize in adequate amounts during stressful conditions like trauma and sepsis. It is an oxidative fuel for enterocytes, lymphocytes and plays an important role in maintaining homeostasis with respect to nitrogen balance, acid-base balance and glucose metabolism. Number of clinical and experimental studies demonstrated its importance as a dietary supplement in maintaining gastrointestinal mucosal barrier function and in preventing bacterial and endotoxin translocation during parenteral nutrition, sepsis, infection, radiation and other various catabolic stress conditions. Hence Glutamine is an essential nutrient for gut mucosal epithelial cell growth, differentiation, mucosal integrity and barrier function. Several cell culture studies further confirm its role in the regulation of mucosal epithelial tight junction integrity. L-Glutamine protects tight junctions in Caco-2 cell monolayers and human colonic mucosa from acetaldehyde-induced permeability change and redistribution of tight junction and adherens junction proteins from the intercellular junctions. This protective effect of L-glutamine appears to be mediated by the transactivation of EGF receptor leading to activation of PKC and MAPK.

There is ample evidence to indicate that L-glutamine is the essential dietary supplement to help maintain mucosal integrity and barrier function under physiologic and pathophysiologic conditions. Human gut has little capacity to synthesize Glutamine and therefore it relies on the glutamine supply by other tissues and diet. Over the last decades of clinical trials of glutamine supplementation in critical illness, 


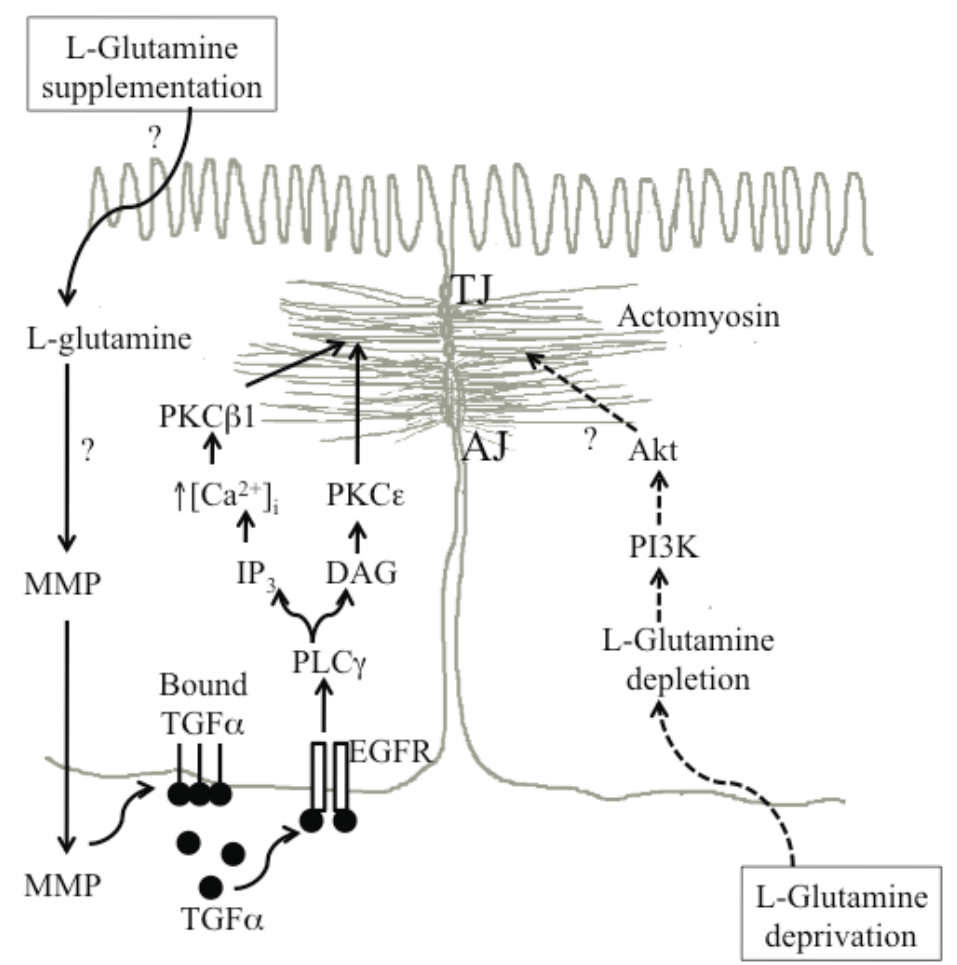

Fig. (1). Schematic representation of potential mechanism involved in L-glutamine-mediated epithelial protection. L-Glutamine supplementation induces transactivation of EGF receptor (EGFR) potentially by excreting metalloproteinases (MMP), which in turn releases membrane bound TGF $\alpha$ and potentially other EGFR ligands leading to EGFR activation. EGFR activation leads to stabilization of actomyosin and tight junctions by a mechanism that involves activation of PLC $\gamma$, PKC $\beta$ I and PKCE. Glutamine deprivation on the other hand leads to activation of P13K and Akt. TGF, transforming growth factor; PLC, phospholipase C; PKC, protein kinase C; IP3, inositol trisphosphate; DAG, diacylglycerol; TJ, tight junciton; AJ, adherens junction; PI3K, phosphotidylinositol 3-kinase. The symbol "?" indicates the lack information regarding the potential mechanism in that process.

surgical stress and cancer have shown significant benefit by reducing the rate of mortality, length of hospital stay and infectious morbidity. Parenteral glutamine administration $(>0.25-0.3 \mathrm{~g} / \mathrm{kg} /$ day) demonstrated the greatest benefit in hospitalized patients [86]. Glutamine-based oral rehydration therapy (ORT) was found to be as effective as glucose-based ORT for rehydration, however with additional benefit with regard to repair of intestinal barrier in patients with diarrhea [53].

Therefore, a growing body of evidence advocates the use of L-glutamine in the clinical practice. Further understanding and application of glutamine-based therapeutics can be enhanced by future studies geared toward our understanding of the molecular mechanisms associated with glutaminemediated protection of gastrointestinal epithelial tight junctions and the mucosal barrier function.

\section{CONFLICT OF INTEREST}

None declared.

\section{ABBREVIATIONS}

AG1478 = 4-(-3-chloroanilino)-6,7-dimethoxyquinozoline

TPN = Total parenteral nutrition

IBD = Inflammatory bowel disease

ERK = Extracellular signal-regulated kinase

MAPK = Mitogen-activated protein kinase

$$
\begin{aligned}
& \text { EGF }=\text { Epidermal growth factor } \\
& \text { EGFR }=\text { EGF receptor } \\
& \text { PI3K }=\text { Phosphatidylinositol 3-kinase } \\
& \text { TER }=\text { Transepithelial electrical resistance } \\
& \text { ZO-1, = Zona occludens-1, -2 \&-3, GSH, glutathione } \\
& \text { ZO-2 \& } \\
& \text { ZO-3 }
\end{aligned}
$$

\section{ACKNOWLEDGEMENTS}

Preparation of this chapter was supported by National Institute of Health grants R01-DK55532 and R01-AA12307.

\section{REFERENCES}

[1] Lacey JM, Wilmore DW. Is glutamine a conditionally essential amino acid? Nutr Rev 1990; 48: 297 -309.

[2] Newsholme P, Lima MM, Procopio J, et al. Glutamine and glutamate as vital metabolites. Braz J Med Biol Res 2003; 36: 153-63.

[3] Young VR, Ajami AM. Glutamine. the emperor or his clothes? J Nutr 2001; 131(Suppl 9): 2449S-59S; discussion 86S-7S.

[4] Boza JJ, Maire J, Bovetto L, Ballevre O. Plasma glutamine response to enteral administration of glutamine in human volunteers (free glutamine versus protein-bound glutamine). Nutrition 2000; 16: $1037-42$.

[5] Wilmore DW. The effect of glutamine supplementation in patients following elective surgery and accidental injury. J Nutr 2001; 131: 2543S-9S; discussion 50S-1 S.

[6] Walsh NP, Blannin AK, Clark AM, Cook L, Robson PJ, Gleeson M. The effects of high-intensity intermittent exercise on the plasma 
concentrations of glutamine and organic acids. Eur J Appl Physiol Occup Physiol 1998; 77: 434-8.

[7] Walsh NP, Blannin AK, Robson PJ, Gleeson M. Glutamine, exercise and immune function. Links and possible mechanisms. Sports Med 1998; 26: 177-91.

[8] Oehler R, Pusch E, Dungel P, et al. Glutamine depletion impairs cellular stress response in human leucocytes. Br J Nutr 2002; 87 (Suppl 1): S17-21.

[9] Engel JM, Muhling J, Weiss S, et al. Low plasma glutamine after multiple trauma: relationship with intracellular glutamine in polymorphonuclear neutrophils during prolonged ICU stay. Acta Anaesthesiol Scand 2003; 47: 707-13.

[10] Haussinger D. Nitrogen metabolism in liver: structural and functional organization and physiological relevance. Biochem 1990; 267: 281-90.

[11] Gstraunthaler G, Holcomb T, Feifel E, Liu W, Spitaler N, Curthoys NP. Differential expression and acid-base regulation of glutaminase mRNAs in gluconeogenic LLC-PK(1)-FBPase(+) cells. Am J Physiol Renal Physioi 2000; 278: F227-37.

[12] Curthoys NP, Gstraunthaler G. Mechanism of increased renal gene expression during metabolic acidosis. Am J Physiol Renal Physioi 2001; 281: F381-90.

[13] Neu J, Shenoy V, Chakrabarti R. Glutamine nutrition and metabolism: where do we go from here? FASEB J 1996; 10: 829-37.

[14] Newsholme EA, Parry-Billings M. Properties of glutamine release from muscle and its importance for the immune system. JPEN J Parenter Enteral Nutr 1990; 4: 63S-7S.

[15] Garcia C, Pithon-Curi TC, de Lourdes Firmano M, Pires de Melo M, Newsholme P, Curi R. Effects of adrenaline on glucose and glutamine metabolism and superoxide production by rat neutrophils. Clin Sci (Lond) 1999; 96: 549-55.

[16] Pithon-Curi TC, Schumacher RI, Freitas JJ, et al. Glutamine delays spontaneous apoptosis in neutrophils. Am J Physiol Cell Physiol 2003; 284: C1355-61.

[17] Fuchs BC, Bode BP. Stressing out over survival: glutamine as an apoptotic modulator. J Surg Res 2006; 131: 26-40.

[18] Medina MA, Marquez J, Nunez de Castro 1. Interchange of amino acids between tumor and host. Biochem Med Metab Biol 1992; 48: $1-7$.

[19] Bode BP. Recent molecular advances in mammalian glutamine transport. J Nutr 2001; 13 1: 2475S-85S; discussion 86S-7S.

[20] Neu J. Glutamine in the fetus and critically ill low birth weight neonate: metabolism and mechanism of action. J Nutr 2001; 131: 2585S-9S; discussion 90S.

[21] Miller AL. Therapeutic considerations of L-glutamine: a review of the literature. Altern Med Rev 1999; 4: 239-48.

[22] Giusti-Paiva A, De Castro M, Antunes-Rodrigues J, Carnio EC. Inducible nitric oxide synthase pathway in the central nervous system and vasopressin release during experimental septic shock. Crit Care Med 2002; 30: 1306-10.

[23] Peng ZY, Hamiel CR, Banerjee A, Wischmeyer PE, Friese RS, Wischmeyer P. Glutamine attenuation of cell death and inducible nitric oxide synthase expression following inflammatory cytokine-induced injury is dependent on heat shock factor-1 expression. JPEN J Parenter Enteral Nutr 2006; 30: 400-6; discussion 6-7.

[24] Yuneva M, Zamboni N, Oefner P, Sachidanandam R, Lazebnik Y. Deficiency in glutamine but not glucose induces MYC-dependent apoptosis in human cells. J Cell Biol 2007; 178: 93-105.

[25] Labow BI, Souba WW. Glutamine. World J Surg 2000; 24: 1503-13.

[26] Pedersen BK, Hoffman-Goetz L. Exercise and the immune system: regulation, integration, and adaptation. Physiol Rev 2000; 80: 1055-81.

[27] Bengmark S. Ecological control of the gastrointestinal tract. The role of probiotic flora. Gut 1998; 42: 2-7.

[28] Dignass AU. Mechanisms and modulation of intestinal epithelial repair. Inflamm Bowel Dis 2001; 7: 68-77.

[29] Duggan C, Gannon J, Walker WA. Protective nutrients and functional foods for the gastrointestinal tract. Am J Clin Nutr 2002; 75: 789-808.

[30] Bengmark S, Jeppsson B. Gastrointestinal surface protection and mucosa reconditioning. JPEN J Parenter Enteral Nutr 1995; 19: 410-5.

[31] El-Kadi SW, Baldwin RLt, McLeod KR, Sunny NE, Bequette BJ. Glutamate is the major anaplerotic substrate in the tricarboxylic acid cycle of isolated rumen epithelial and duodenal mucosal cells from beef cattle. J Nutr 2009; 139: 869-75.

[32] Neu J, DeMarco V, Li N. Glutamine: clinical applications and mechanisms of action. Curr Opin Clin Nutr Metab Care 2002; 5 : 69-75.

[33] Platell C, McCauley R, McCulloch R, Hall J. The influence of parenteral glutamine and branched-chain amino acids on total parenteral nutrition-induced atrophy of the gut. JPEN J Parenter Enteral Nutr $1993 ; 17: 348-54$.

[34] Wilmore DW, Smith RJ, O'Dwyer ST, Jacobs DO, Ziegler TR, Wang XD. The gut: a central organ after surgical stress. Surgery 1988; 104: 917-23

[35] Xue H, Sawyer MB, Field CJ, Dieleman LA, Murray D, Baracos VE. Bolus oral glutamine protects rats against CPT -II-induced diarrhea and differentially activates cytoprotective mechanisms in host intestine but not tumor. J Nutr 2008; 138: 740-6.

[36] Burrin DG, Shulman RJ, Langston C, Storm MC. Supplemental alanylglutamine, organ growth, and nitrogen metabolism in neonatal pigs fed by total parenteral nutrition. JPEN J Parenter Enteral Nutr 1994; 18: 313-9.

[37] Nakamura E, Hagen SJ. Role of glutamine and arginase in protection against ammonia-induced cell death in gastric epithelial cells Am J Physiol Gastrointest Liver Physioi 2002; 283: G 1264-75.

[38] Tamada H, Nezu R, Imamura I, et al. The dipeptide alanyl-glutamine prevents intestinal mucosal atrophy in parenterally fed rats. JPEN J Parenter Enteral Nutr 1992; 16: 110-6.

[39] Windmueller HG, Spaeth AE. Uptake and metabolism of plasma glutamine by the small intestine. J BioI Chern 1974; 249: 5070-9.

[40] Savarese DM, Savy G, Vahdat L, Wischmeyer PE, Corey B. Prevention of chemotherapy and radiation toxicity with glutamine. Cancer Treat Rev 2003; 29: 501-13.

[41] Yoshida S, Matsui M, Shirouzu Y, Fujita H, Yamana H, Shirouzu K. Effects of glutamine supplements and radiochemotherapy on systemic immune and gut barrier function in patients with advanced esophageal cancer. Ann Surg 1998; 227: 485-91.

[42] Coeffier M, Claeyssens S, Hecketsweiler B, Lavoinne A, Ducrotte $\mathrm{P}$, Dechelotte P. Enteral glutamine stimulates protein synthesis and decreases ubiquitin mRNA level in human gut mucosa. Am J Physiol Gastrointest Liver Physiol 2003; 285: G266-73.

[43] Yoshida S, Leskiw MJ, Schluter MD, et al. Effect of total parenteral nutrition, systemic sepsis, and glutamine on gut mucosa in rats. Am J Physiol 1992; 263(2 Pt 1): E368-73.

[44] Newsholme P, Procopio J, Lima MM, Pithon-Curi TC, Curi R. Glutamine and glutamate - their central role in cell metabolism and function. Cell Biochem Funct 2003; 21: 1-9.

[45] Wu G, Meier SA, Knabe DA. Dietary glutamine supplementation prevents jejunal atrophy in weaned pigs. J Nutr 1996; 126 2578-84.

[46] He Y, Sanderson IR, Walker W A. Uptake, transport and metabolism of exogenous nucleosides in intestinal epithelial cell cultures. J Nutr 1994; 124: 1942-9.

[47] Ko TC, Beauchamp RD, Townsend CM Jr, Thompson JC. Glutamine is essential for epidermal growth factor-stimulated intestinal cell proliferation. Surgery 1993; 114: 14753; discussion 53-4.

[48] Rhoads M. Glutamine signaling in intestinal cells. JPEN J Parenter Enteral Nutr 1999; 23: S38-40.

[49] Wolfgang CL, Lin C, Meng Q, Karinch AM, Vary TC, Pan M. Epidermal growth factor activation of intestinal glutamine transport is mediated by mitogen-activated protein kinases. J Gastrointest Surg 2003; 7: 149-56.

[50] Elia M, Lunn PG. The use of glutamine in the treatment of gastrointestinal disorders in man. Nutrition 1997; 13: 743-7.

[51] Peng X, Yan H, You Z, Wang P, Wang S. Effects of enteral supplementation with glutamine granules on intestinal mucosal barrier function in severe burned patients. Burns 2004; 30: 135-9.

[52] DeMarco VG, Li N, Thomas J, West CM, Neu J. Glutamine and barrier function in cultured Caco-2 epithelial cell monolayers. J Nutr 2003; 133: 2176-9.

[53] Guerrant RL, Oria RB, Moore SR, Oria MO, Lima AA. Malnutrition as an enteric infectious disease with long-term effects on child development. Nutr Rev 2008; 66: 487505.

[54] Lima NL, Soares AM, Mota RM, Monteiro HS, Guerrant RL, Lima AA. Wasting and intestinal barrier function in children taking alanyl-glutamine-supplemented enteral formula. J Pediatr Gastroenterol Nutr 2007; 44: 365-74. 
[55] Fujita T, Sakurai K. Efficacy of glutamine-enriched enteral nutrition in an experimental model of mucosal ulcerative colitis. Br J Surg 1995; 82: 749-51.

[56] Li J, Langkamp-Henken B, Suzuki K, Stahlgren LH. Glutamine prevents parenteral nutrition-induced increases in intestinal permeability. JPEN J Parenter Enteral Nutr 1994; 18: 303-7.

[57] De-Souza DA, Greene LJ. Intestinal permeability and systemic infections in critically ill patients: effect of glutamine Crit Care Med 2005; 33: 1125-35.

[58] Quan ZF, Yang C, Li N, Li JS. Effect of glutamine on change in early postoperative intestinal permeability and its relation to systemic inflammatory response. World J Gastroenterol 2004; 10: 1992-4.

[59] Foitzik T, Stufler M, Hotz HG, et al. Glutamine stabilizes intestinal permeability and reduces pancreatic infection in acute experimental pancreatitis. J Gastrointest Surg 1997; 1: 40-6; discussion 6-7.

[60] Kanauchi O, Iwanaga T, Mitsuyama K. Germinated barley foodstuff feeding. A novel neutraceutical therapeutic strategy for ulcerative colitis. Digestion 2001; 63 (Suppl 1): 60-7.

[61] Mitic LL, Anderson 1M. Molecular architecture of tight junctions. Annu Rev Physiol 1998; 60: 121-42.

[62] Anderson JM, Van Itallie CM. Tight junctions and the molecular basis for regulation of paracellular permeability. Am J Physiol 1995; 269: G467-75.

[63] Van Hallie CM, Anderson IM. Claudins and epithelial paracellular transport. Annu Rev Physiol 2006; 68: 403-29.

[64] Rao R. Oxidative stress-induced disruption of epithelial and endothelial tight junctions. Front Biosci 2008; 13: 7210-26.

[65] Berkes J, Viswanathan VK, Savkovic SD, Hecht G. Intestinal epithelial responses to enteric pathogens: effects on the tight junction barrier, ion transport, and inflammation. Gut 2003; 52: 439-51.

[66] Rao R. Endotoxemia and gut barrier dysfunction in alcoholic liver disease. Hepatology 2009; 50: 638-44.

[67] Panigrahi P, Gewolb IH, Bamford P, Horvath K. Role of glutamine in bacterial transcytosis and epithelial cell injury. JPEN J Parenter Enteral Nutr 1997; 21: 75-80.

[68] Potsic B, Holliday N, Lewis P, Samuelson D, DeMarco V, Neu J. Glutamine supplementation and deprivation: effect on artificially reared rat small intestinal morphology. Pediatr Res 2002; 52: 430-6.

[69] Maes M, Leunis Jc. Normalization of leaky gut in chronic fatigue syndrome (CFS) is accompanied by a clinical improvement: effects of age, duration of illness and the translocation ofLPS from gram-negative bacteria. Neuro Endocrinol Lett 2008; 29: 902-10.

[70] Harward TR, Coe D, Souba WW, Klingman N, Seeger IM. Glutamine preserves gut glutathione levels during intestinal ischemia/reperfusion. J Surg Res 1994; 56: 351-5.

[71] Kozar RA, Schultz SG, Bick RJ, Poindexter BJ, DeSoignie R, Moore FA. Enteral glutamine but not alanine maintains small bowel barrier function after ischemia/reperfusion injury in rats. Shock 2004; 21: 433-7.
[72] Schwarz B, Salak N, Hofstotter H, et al. [Intestinal ischemic reperfusion syndrome: pathophysiology, clinical significance, therapy]. Wi en Klin Wochenschr 1999; 111: 539-48.

[73] Hond ED, Peeters M, Hiele M, Bulteel V, Ghoos Y, Rutgeerts P. Effect of glutamine on the intestinal permeability changes induced by indomethacin in humans. Aliment Pharmacol Ther 1999; 13: 679-85.

[74] White JS, Hoper M, Parks RW, Clements WD, Diamond T. Glutamine improves intestinal barrier function in experimental biliary obstruction. Eur Surg Res 2005; 37: 342-7.

[75] Ding LA, Li JS. Effects of glutamine on intestinal permeability and bacterial translocation in TPN-rats with endotoxemia. World J Gastroenterol 2003; 9: 1327-32.

[76] Li N, Lewis P, Samuelson D, Liboni K, Neu 1. Glutamine regulates Caco-2 cell tight junction proteins. Am J Physiol Gastrointest Liver Physiol 2004; 287: G726-33.

[77] Seth A, Basuroy S, Sheth P, Rao RK. L-Glutamine ameliorates acetaldehyde-induced increase in paracellular permeability in Caco-2 cell monolayer. Am J Physiol Gastrointest Liver Physiol 2004; 287: G510-7.

[78] Basuroy S, Sheth P, Mansbach CM, Rao RK. Acetaldehyde disrupts tight junctions and adherens junctions in human colonic mucosa: protection by EGF and L-g lutamine. Am J Physio1 Gastrointest Liver Physiol. 2005; 289: G367-75.

[79] Rao RK. Biologically active peptides in the gastrointestinal lumen. Life Sci 1991; 48: 1685-704.

[80] Rao R, Porreca F. Epidermal growth factor protects mouse ileal mucosa from Triton X-100-induced injury. Eur J Pharmacol 1996; 303: 209-12.

[81] Basuroy S, Seth A, Elias B, Naren AP, Rao R. MAPK interacts with occludin and mediates EGF-induced prevention of tight junction disruption by hydrogen peroxide. Biochem J 2006; 393(Pt 1): 69-77.

[82] Sheth P, Seth A, Thangavel M, Basuroy S, Rao RK. Epidermal growth factor prevents acetaldehyde-induced paracellular permeability in Caco-2 cell monolayer. Alcohol Clin Exp Res 2004; 28 : 797-804.

[83] Suzuki T, Seth A, Rao R. Role of phospholipase Cgamma-induced activation of protein kinase Cepsilon and PKCbetaI in epidermal growth factor-mediated protection of tight junctions from acetaldehyde in Caco-2 cell monolayers. J Biol Chern 2008; 283: 3574-83.

[84] Larson SD, Li J, Chung DH, Evers BM. Molecular mechanisms contributing to glutamine-mediated intestinal cell survival. Am J Physiol Gastrointest Liver Physiol 2007; 293: G 1262-71.

[85] Li N, Neu J. Glutamine deprivation alters intestinal tight junctions via a PI3-KJAkt mediated pathway in Caco-2 cells. J Nutr 2009; 139: 710-4.

[86] Wischmeyer PE. Clinical applications of L-glutamine: past, present, and future. Nutr Clin Pract 2003; 18: 377-85. 